TABLE II

Group $A$ (Total cases morbid $=22$ )

\begin{tabular}{|c|c|c|c|c|c|c|c|c|c|}
\hline \multirow{2}{*}{\multicolumn{3}{|c|}{ Method of Treatment }} & \multicolumn{7}{|c|}{ Site of Infection } \\
\hline & & & 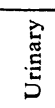 & 吾 & 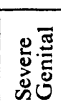 & 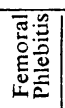 & 吾 & 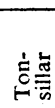 & 号 \\
\hline No treatment & $\ldots$ & .. & - & - & - & - & - & - & - \\
\hline A.R.M. and binder. & .. & .. & 1 & - & - & - & - & - & 1 \\
\hline A.R.M., binder, and & ging & .. & 3 & 11 & 1 & 1 & 2 & 1 & 19 \\
\hline Caesarean section ... & .. & .. & - & - & - & - & - & - & - \\
\hline Plugging + Caesarean & .. & .. & - & - & - & 1 & - & - & 1 \\
\hline Plugging down leg & .. & .. & - & 1 & - & $1-$ & $1-$ & $1-$ & 1 \\
\hline
\end{tabular}

Group B $($ Total cases morbid $=21)$

\begin{tabular}{|c|c|c|c|c|c|c|c|c|c|}
\hline \multirow{2}{*}{\multicolumn{3}{|c|}{ Method of Treatment }} & \multicolumn{7}{|c|}{ Site of Infection } \\
\hline & & & 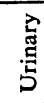 & 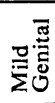 & 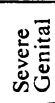 & 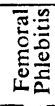 & 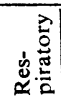 & 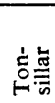 & 胥 \\
\hline No treatment & . & .. & - & 3 & - & - & - & - & 3 \\
\hline A.R.M. and Willett's $f$ & ceps & .. & - & 5 & 1 & - & - & - & 6 \\
\hline A.R.M. and plugging & .. & .. & - & 2 & 1 & - & - & - & 3 \\
\hline Caesarean section ... & .. & .. & - & 1 & - & 1 & 2 & - & 4 \\
\hline Plugging + Caesarean & .. & .. & - & - & - & - & - & - & - \\
\hline Pulling down leg & .. & .. & - & 3 & 1 & 1 & - & - & 5 \\
\hline
\end{tabular}

\section{Consideration of Results}

The 143 cases of Group A were treated according to the method outlined above, and from a study of the figures it is evident that:

1. Many cases (38 per cent.) required only artificial rupture of the membranes and the application of a tight binder. Such cases were lateral or marginal insertions occurring mostly in multiparae admitted in labour. Uniformly good results are to be expected in this type of case, and are obtained in this hospital and elsewhere.

2. Haemorrhage was profuse enough to require immediate steps to arrest it in about half the cases ( 47 per cent.).

3. Plugging the vagina has proved an extremely successful method of achieving haemostasis.

We therefore venture to conclude that the striking decrease in the mortality rate in Group $\mathrm{A}$ is due to : $(a)$ the co-operation and team-work made possible by the standardization of treatment; $(b)$ the prompt arrest of severe haemorrhage by plugging the vagina; $(c)$ replacement of blood loss by transfusion ; $(d)$ treatment of shock before delivery of the patient. A comparison of the total morbidity rates for the two groups-Group A, 15.4 per cent.; Group B, 14.7 per cent.-reveals but little increase in the incidence of sepsis, and the difference in stillbirth rate is negligible.

Out of a total of 286 cases treated, 146 required active intervention per vaginam, excluding those treated by artificial rupture of the membranes only. Seventy-three of these cases were plugged and seventy-three were treated by either pulling down a leg with or without podalic version or the application of Willett's forceps. The plugged series showed two cases of severe and fourteen cases of mild genital infection, and the other series two cases of severe and ten of mild genital infection. The increase in sepsis rate is therefore very small. It is interesting to note that Caesarean section was performed on six occasions, from six to twenty-four hours after plugging, and that only one of these patients had a morbid tem- perature, due to a femoral thrombosis occurring on the twelfth day. We feel that we are entitled to suggest that plugging the vagina for placenta praevia is not attended with an undue liability to sepsis when its morbidity rate is compared with that following other forms of treatment which involve intervention per vaginam.

\section{Summary}

1. The results of treatment of 286 cases of placenta praevia are reviewed.

2. The standard method of treatment at Queen Charlotte's Hospital is described. Emphasis is laid upon the value of a preconceived routine, which included plugging and replacement of blood loss.

3 . We believe that the improvement in the mortality rate is due to this method.

4. Evidence is offered in support of the contention that vaginal plugging in cases of placenta praevia is not associated with a high rate of sepsis when compared with that of other forms of treatment.

In conclusion we should like to thank the members of the honorary staff of Queen Charlotte's Hospital for the use of the case records, and in particular Mr. Leonard Phillips for permission to publish an account of his routine treatment. We also wish to express our appreciation of the work of the labour ward staff, to whose co-operation much of the improvement in results is due.

\section{CONCERNING THE BOX MASK FOR OXYGEN ADMINISTRATION}

BY

\author{
J. ARGYLL CAMPBELL, M.D., D.Sc. \\ (National Institute for Medical Research, Hampstead)
}

The main outline of this method of oxygen administration was originally described in the Journal about two years ago (Campbell, 1936). Since then some additional information (Barach, 1937; Campbell, 1937a, 1937b) has been published. A number of the masks have been used on patients and further data have been obtained, while various criticisms have arisen. These are dealt with below.

\section{Comfort of the Patient}

With the earlier types of mask vision was rather restricted. In more recent types wider vision has been provided by removing the shoulders of the mask and shifting the inlet tube for oxygen from the front of the forehead to a horizontal position inside the mask as in some of the earlier experimental masks. Fig. 1 illustrates the transparent type made of celluloid acetate. This material is neat, but it is not durable and must be washed only in cold water, as warm water or exposure to the sun will warp it. This celluloid acetate is not very inflammable. More durable material is aluminium, which, although greater in cost, is perhaps more suitable for hospital patients. The oxygen enters the mask through perforations in the horizontal portion of tubing inside the mask. These perforations must be directed upwards so that the incoming oxygen strikes the middle of the top of the mask. A bobbin flow-meter records the rate of oxygen flow, and an automatic regulator is used for the cylinder.

Some patients have found the mask rather warm to the face. This was due in some cases to enclosing the cheeks within the mask. The opening at the back of the mask should be bent to include only the nose and mouth, while 
the cheeks should be excluded. Thus only a small portion of the total area of the face is enclosed within the mask, and on warm days more of the skin of the arms may be exposed to the external air to aid loss of body heat. The sensation of warmth is usually only temporary, and is noiiceable mainly during the early period of wearing the mask. In colder atmospheres some prefer the warmth on the face; also, the temperature of the skin of the enclosed portion of the face is not so high as that of the

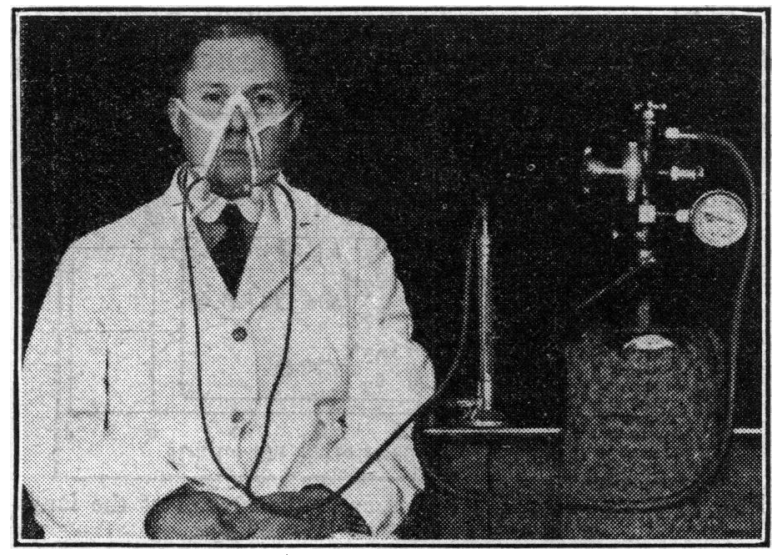

FIG. 1.-Transparent (celluloid acetate) mask in position, with bobbin flow-meter and automatic regulator for gas cylinder. (Photo by L. W. Collison.)

clothed body. The opening at the back of the mask is lined with lint, which is kept in position with adhesive plaster and may be easily renewed. Two or three folds of lint are used to keep the mask airtight against the nose and face.

Expectoration may take place through the lower open end of the mask if a wide-mouthed vessel is used to collect the sputum. Food and medicine may be administered through a door on the front of the mask. An easier method, during meals, is to hold the mask in position by hand and remove it only at the brief periods when food is actually being placed in the mouth. In any case breathing usually ceases at this moment.

This type of mask has been used on some patients for prolonged periods, up to six weeks, without any greater discomfort than with other methods. Its advantages have been stated in the earlier papers. It has an advantage over nasal methods in that it may be used when the nasal passages are blocked. In emergency a box mask may be made from a cardboard box and a rubber tube in ten minutes (Campibell, 1936).

\section{Oxygen Pressure Inside the Mask}

Analysis of the gas inside the mask was carried out with Haldane's large apparatus, using about $5 \mathrm{c.cm}$. of the gas mixed with about $15 \mathrm{c.cm}$. of nitrogen. Samples were taken, either at the end of inspiration or of expiration, by means of an evacuated sample tube to the upper end of which a fine-bore glass tube, filled with mercury, was attached. The position in the mask from which the samples were withdrawn was important. It was 2 to $3 \mathrm{~cm}$. to the right of the nose, at a level of about $1 \mathrm{~cm}$. above the opening in the right nostril. This point was regarded as being equally affected by the incoming oxygen at the top of the mask and the incoming air, or expired air, at the lower end of the mask. The gas obtained probably approximated in composition to that inspired by the subject under observation. The subject (C. P.) was 44 years of age, weighed $64.5 \mathrm{~kg}$., and was $157.5 \mathrm{~cm}$. in height; his respiratory volume, while sitting quietly under normal conditions, was about 7.5 litres per minute. Two gases were used-pure oxygen and a mixture of 7 per cent. carbon dioxide with 93 per cent. oxygen. Fig. 2 records the results for oxygen pressure in percentages of an atmosphere with different rates of flow of the special gases. The oxygen percentages within the mask are slightly

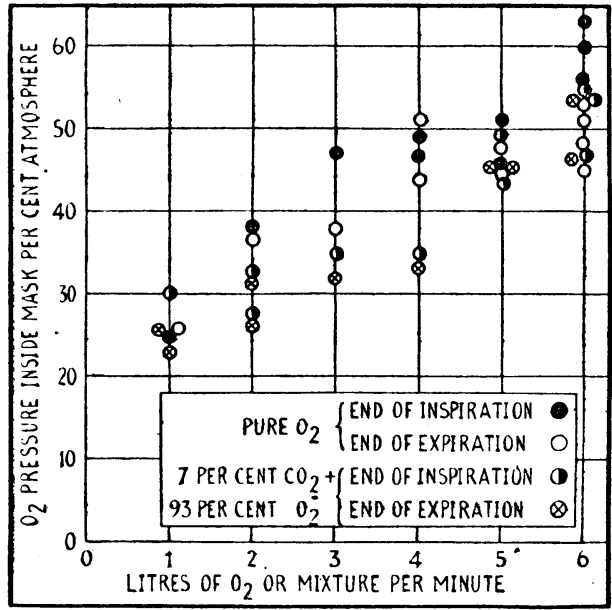

Fig. 2.- Oxygen pressures at the end of inspiration and of expiration inside the mask, just above level of right nostril, with various rates of flow of gas.

higher when pure oxygen is used than with the carbon dioxide mixture. Also, as a rule the percentages at the end of inspiration are slightly higher than those at the end of expiration. With 6 litres of the special gases per minute the oxygen percentages in the mask are usually between 50 and 60 , and with 1 litre per minute they are between 20 and 30 .

\section{Oxygen Pressure in the Lung Abeoli}

Using Haldane's technique, samples of alveolar air were taken at the end of an ordinary inspiration, immediately after removal of the mask from the face. Generally

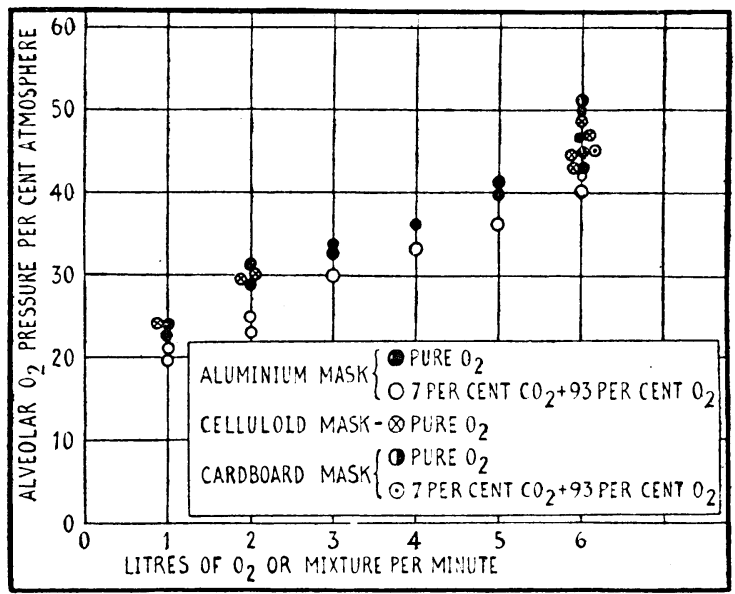

FIG. 3.-Oxygen pressures in the lung alveoli, with various rates of flow of gas.

speaking, the alveolar oxygen pressures (Fig. 3) are about 10 per cent. lower than the oxygen pressures within the mask (Fig. 2). Thus at 6 litres of pure oxygen per minute the oxygen pressures in the alveoli of the lung are about 40 to 50 per cent. With the carbon dioxide mixture the alveolar oxygen pressures are slightly lower than with pure oxygen. The various masks tested give similar results. 


\section{Carbon Dioxide Pressure Inside the Mask}

This was measured at the same point as the oxygen pressure inside the mask. The results (Fig. 4) indicate that with 6 litres of pure oxygen per minute the carbon dioxide pressure averages about 1 per cent. and does not rise

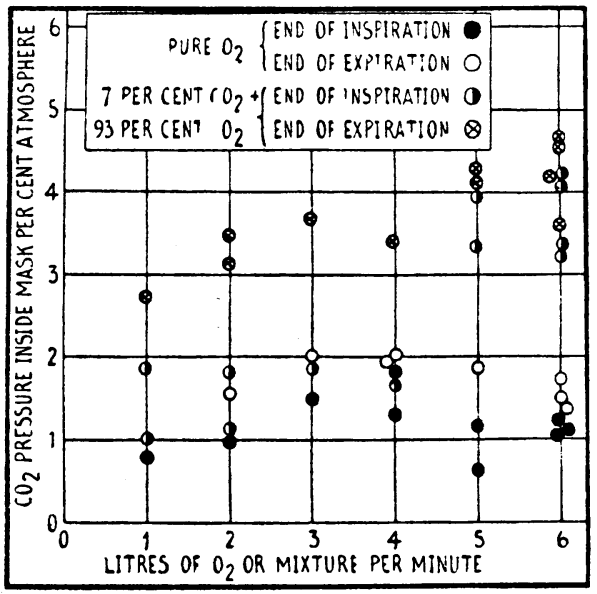

Fig. 4.-Carbon dioxide pressures at the end of inspiration and of expiration inside the mask, just above level of right nostril, with various rates of flow of gas.

above 2 per cent. Most patients will not be affected by such concentrations of carbon dioxide. It is known from experience in submarines that discomfort is not noticeable until the carbon dioxide pressure reaches 3 per cent. Also, certain patients, according to the teaching of Yandell Henderson, are benefited by carbon dioxide as a respiratory stimulant, and he advocates from 5 to 10 per cent. To obtain about 5 per cent. inside the mask it is necessary to use a mixture of 7 per cent. carbon dioxide and 93 per cent. oxygen at a flow of 6 litres per minute (Fig. 4). Breathing about 5 per cent. of carbon dioxide increased the volume breathed by the present subject from the normal figure of 7.5 litres to about 12 litres per minute; depth-not rate-of breathing was increased. With a more rapid flow and mixtures containing higher percentages of carbon dioxide, the carbon dioxide pressure in the mask may be further increased. In cases of carbon monoxide poisoning 10 per cent. carbon dioxide with 90 per cent. oxygen is advisable with this mask until respiration is well established, when pure oxygen should be used (Campbell, 1937a).

\section{Carbon Dioxide Pressure in the Lung Alveoli}

Fig. 5 gives the results for carbon dioxide pressure in the alveoli of the lung under similar conditions. Normally the subject employed has an alveolar carbon dioxide pressure of about 5 per cent. The mask being worn and pure oxygen flowing from 1 to 6 litres per minute, the alveolar carbon dioxide pressure is usually somewhere between 5 and 6 per cent. The increase in alveolar carbon dioxide pressure above the normal is not necessarily due to the mask, because administration of oxygen at high percentage by any method tends to increase the carbon

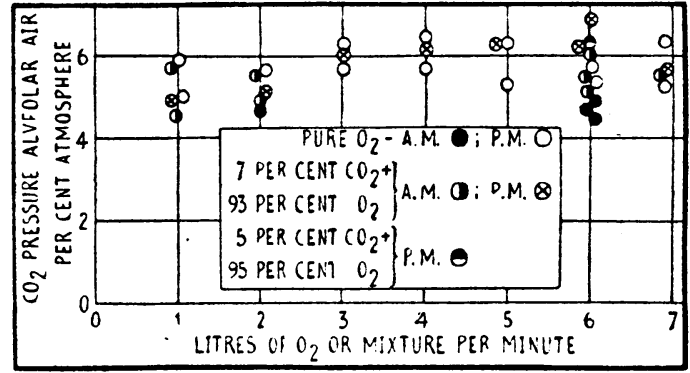

FIG. 5.-Carbon dioxide pressures in the alveoli of the lung, with various rates of flow of gas.

dioxide pressure in the tissues, and similar alveolar carbon dioxide pressures are obtained with other methods. With 6 litres of pure oxygen the alveolar figures are usually lower one to three hours after lunch compared with samples taken four hours after breakfast. Such variations are connected with the acid-base changes concerned with digestion or other factors. At 6 litres per minute, and with the mixture of 7 per cent. carbon dioxide and 93 per cent. oxygen, there is a slight further increase in alveolar carbon dioxide pressure.

All the observations recorded in the charts in Figs. 2 to 5 were made in a room with the temperature purposely on the warm side-that is, at about $20^{\circ} \mathrm{C}$. and a katathermometer cooling power 5 to 6 , with air velocity usually between 20 and 40 feet per minute. These are fairly comfortable indoor conditions for a patient in summer weather.

\section{Position of the Mask and Effects of Draught}

In draughty wards the mask should be adjusted so that its lower front edge is about $3 \mathrm{~cm}$. above the chest, or the head of the bed should be screened. As pointed out before

Table showing Effects of Draughts and Their Correction: $\mathrm{O}_{2}$ Flow 6 Litres per Minute

\begin{tabular}{|c|c|c|c|c|c|c|c|c|c|}
\hline \multirow{2}{*}{$\begin{array}{l}\text { Expt. } \\
\text { No. }\end{array}$} & \multirow{2}{*}{ Date } & \multirow{2}{*}{ Temp. ${ }^{\circ} \mathrm{C}$. } & \multirow{2}{*}{$\begin{array}{l}\text { Cooling } \\
\text { Power }\end{array}$} & \multirow{2}{*}{$\begin{array}{l}\text { Air Velocity } \\
\text { (ft. per min.) }\end{array}$} & \multicolumn{2}{|c|}{$\begin{array}{l}\text { Alveolar Pressures } \\
\text { per cent. atm. }\end{array}$} & \multicolumn{3}{|c|}{ Conditions of Mask } \\
\hline & & & & & $\mathrm{CO}_{3}$ & $\mathrm{O}_{2}$ & Mask & $\begin{array}{l}\text { Curtain } \\
\text { Used }\end{array}$ & $\begin{array}{c}\text { Position } \\
\text { (cm. above chest) }\end{array}$ \\
\hline 1 & $29 / 10 / 37$ & 22.0 & 8.6 & 200 & 5.7 & 28.5 & Cellutoid & Nil & 3 \\
\hline 2 & $1 / 11 / 37$ & 20.0 & 6.0 & 40 & 5.7 & 40.5 & ", & $"$ & $"$ \\
\hline 3 & $18 / 11 / 37$ & 20.5 & 8.8 & 160 & 5.8 & 31.0 & Aluminium & " & " \\
\hline 4 & $1 / 11 / 37$ & 20.0 & 10.0 & 210 & 5.8 & 45.0 & Celluloid & Lint & " \\
\hline 5 & $2 / 12 / 37$ & 23.0 & 4.8 & 40 & 6.5 & 53.0 & Aluminium & Cardboard & 10 \\
\hline 6 & $13 / 11 / 36$ & 20.5 & 5.0 & 20 & 5.9 & 40.0 & $"$ & Nil & " \\
\hline $7 a$ & $3 / 12 / 37$ & 21.5 & 10.0 & 215 & 5.9 & 36.2 & $"$ & $\begin{array}{l}\text { Entire card- } \\
\text { board (two- }\end{array}$ & " \\
\hline $\mathbf{7 b}$ & " & $\bullet$ & $\cdot n$ & $"$ & 5.9 & 35.8 & " & $\begin{array}{l}\text { thirds closed) } \\
\text { Cardboard } \\
\text { grid }\end{array}$ & $\boldsymbol{n}$ \\
\hline $7 c$ & " & & & & 5.7 & 35.0 & " & ") & " \\
\hline $7 d$ & $"$ & $"$ & $"$ & $"$ & 5.8 & 28.8 & " & Nil & $"$ \\
\hline
\end{tabular}


(Campbell, 1937a), if the head is raised so that this edge is $10 \mathrm{~cm}$. above the chest the efficiency of the mask is affected somewhat by draughts, so that with 6 litres of pure oxygen per minute the alveolar oxygen pressure is about 30 to 40 per cent. in place of 40 to 50 . The chest acts as a damper to draughts, so that with the mask nearer the chest less oxygen is lost from the mask and fewer draughts of air enter the mask. In patients with a long neck the mask may be made longer and narrower without change in volume of inside space, but a simpler corrective is to partially close the botton of the ordinary mask (see Table, Experiment 5).

Dr. R. V. Christie also kindly pointed out that draughts affect the efficiency to some extent. My results for the effects of draughts are given in the table, using an oxygen flow of 6 litres per minute in all cases.

With an air velocity of 40 feet per minute and the front edge of the mask $3 \mathrm{~cm}$. from the chest, the alveolar oxygen pressure is about 40 per cent. (Experiment 2); with an air velocity of 160 to 200 feet per minute the oxygen pressure is lowered to about 30 per cent. (Experiments 1 and 3 ). The effect of such a draught is easily countered by fixing with adhesive tape a curtain of lint about $8 \mathrm{~cm}$. in length all round the bottom of the mask, as in Experiment 4 in the table; the alveolar oxygen pressure is 45 per cent. in spite of an air velocity of 210 feet per minute.

In Experiment 5, with the head held up and the mask $10 \mathrm{~cm}$. from the chest, the alveolar oxygen pressure is kept at a high level, 53 per cent., by closing the lower end of the mask with a cardboard grid, containing air spaces $1 \mathrm{~cm}$. square alternating with portions of solid cardboard of the same dimensions. In Experiment 6, with lower air velocity, it is shown that no closure of the bottom of the mask is required. In Experiment $7 \mathrm{~d}$ in the table, with an air velocity of 215 feet per minute and the lower edge of the mask $10 \mathrm{~cm}$. from the chest and the bottom of the mask freely open, the alveolar oxygen pressure is lowered to about 29 per cent., but by means of the perforated cardboard grid or by closing two-thirds of the lower end of the mask with a piece of entire cardboard the alveolar oxygen pressure is raised to about 35 per cent. (Experiments $7 \mathrm{a}, 7 \mathrm{~b}$, and $7 \mathrm{c}$ ). The curtain of lint is the most efficient means of protecting against draughts, but under ordinary circumstances the head of the bed may be provided with screens so that no special closing of the lower end is required. If the patient is restless and moves the head about much, then the bottom of the mask may be closed by one of the above methods to gain greater efficiency. Even at the worst, with the bottom of the mask open and in a draught, the patient is still getting oxygen in the lungs at a pressure of about 30 per cent.- - that is, more than double the normal-with a flow of 6 litres of oxygen per minute.

For sedentary individuals Sir Leonard Hill and others have recommended air velocities of 3,7 , and 17 metres per minute, with air temperatures $15^{\circ}, 18^{\circ}$, and $21^{\circ}$ C. respectively. Under these conditions the mask gives about 40 to 50 per cent. of oxygen in the alveoli of the lungs with a flow of 6 litres of oxygen per minute.

Dr. A. L. Barach (personal communication) uses a small injector on the oxygen inlet tube so that some air is drawn in; this increases the flow through the mask, which is reduced in size. This draught helps to remove carbon dioxide and cools the face, but may be too rapid and so disturb certain types of patients. He uses also a whistle arrangement which gives warning when the oxygen tube is kinked. He recommends the apparatus for patients and for passengers in aeroplanes (Barach, 1937).

\section{Summary}

1. The recent type of mask made of aluminium or transparent celluloid acetate for oxygen administration is described. Vision is now much wider. The comfort of the patient is considered.

2. With 6 litres of pure oxygen per minute the oxygen pressure in the alveoli of the lung is kept at about 40 to 50 per cent. under ordinary comfortable conditions of ventilation.

3. With 6 litres per minute of a mixture of 7 per cent. carbon dioxide and 93 per cent. oxygen the patient breathes about 5 per cent. of carbon dioxide, and the alveolar oxygen pressure is about 40 to 45 per cent. This or a similar mixture may be used when a respiratory stimulant is required.

4. The effects of draughts and of the position of the mask on its efficiency are considered. Simple means of counteracting effects of excessive draughts or excessive movement of the head are given.

I am indebted to Mr. C. Pergande, who acted as subject in the observations. The mask may be obtained from Messrs. Siebe, Gorman and Co., 187, Westminster Bridge Road, S.E.1.

\section{REFERENCES}

Barach, A. L. (1937). J. Amer. med. Ass., 108, 1868

Campbell, J. Argyll (1936). British Medical Journal, 1, 1245. (1937a). Lancet, 1,82.

(1937b). British Medical Journal, 1, 526

\section{INTRANASAL APPLICATION OF POLLEN SOLUTION IN HAY FEVER}

\author{
BY
}

\section{CLEMENT FRANCIS, M.A., M.B., B.Ch.}

Surgeon, Metropolitan Ear, Nose and Throat Hospital

The object of this short article is to describe a method of treatment which I have found useful during recent years in relieving hay fever. I have employed it in numerous cases, either alone or in conjunction with other means; and I find it invaluable both as a preventive of attacks and for use in relieving an already existing attack.

\section{Technique}

The method is extremely simple, and consists in spraying the nasal cavities with a few drops of a sterile solution of grass pollen. The solution should be applied to the septum, the middle and inferior turbinals, and in particular to any hypersensitive areas. If this is done during the season in the case of a hay fever patient the immediate effect will be to produce a short bout of sneezing followed by the usual symptoms of hay fever. The effects of this artificially produced attack quickly subside, and the patient then becomes more resistant to the pollen in the air, with the result that, for several days to a week or more, many patients remain free from all symptoms of hay fever. The procedure may, if necessary, then be repeated.

The method above described may with advantage be used in conjunction with other means of treatment, and if there are any abnormally sensitive areas in the nose I make it a practice to treat these (Francis, 1934) before applying the pollen solution. If carefully carried out both 